\title{
Development of droplet characteristics prediction models for air induction nozzles based on wind tunnel tests
}

\author{
Juan Liao ${ }^{1,2,3,4}$, Andrew John Hewitt ${ }^{4}$, Pei Wang ${ }^{1,2,3,5}$, Xiwen Luo ${ }^{1,2,3}$, Ying Zang ${ }^{1,2,3}$, \\ Zhiyan Zhou ${ }^{1,2,3}$, Yubin Lan ${ }^{1,2,3}$, Chris O'Donnell ${ }^{4}$ \\ (1. College of Engineering, South China Agricultural University/Engineering Research Center for Agricultural Aviation Application \\ (ERCAAA), Guangzhou 510642, China; 2. Key Laboratory of Key Technology on Agricultural Machine and Equipment \\ (South China Agricultural University), Ministry of Education, Guangzhou 510642, China; \\ 3. National Joint Research Center for Precision Agricultural Aviation Application Technology, Guangzhou 510642, China; \\ 4. The University of Queensland, Gatton, Queensland 4343, Australia; \\ 5. School of Electrical and Information Engineering, Jiangsu University, Zhenjiang 212013, China)
}

\begin{abstract}
Nozzle flowrate and spray pressure are two of the most important factors influencing on droplet characteristics. With the aim to develop prediction models for air-induction nozzles (AINs), a series of Billericay Farm Services (BFS) AINs with different orifice diameters in combination with tap water were tested. $0.2 \mathrm{MPa}, 0.3 \mathrm{MPa}, 0.4 \mathrm{MPa}, 0.5 \mathrm{MPa}, 0.6 \mathrm{MPa}$ and $0.7 \mathrm{MPa}$ of spray pressures and $2 \mathrm{~m} / \mathrm{s}, 3 \mathrm{~m} / \mathrm{s}, 4 \mathrm{~m} / \mathrm{s}$ and $5 \mathrm{~m} / \mathrm{s}$ of air speeds were setup. Based on the wind tunnel tests data, prediction models with input variables of nozzle flowrate and spray pressure and output variables of $\mathrm{D}_{\mathrm{v} 0.1}, \mathrm{D}_{\mathrm{v} 0.5}$, $\mathrm{D}_{\mathrm{v} 0.9}, \%<150 \mu \mathrm{m}$ (proportion of spray volume contained in droplets with diameter below $150 \mu \mathrm{m}$ ), relative span (RS) and coefficient of variation $(\mathrm{CV})$ of $\mathrm{D}_{\mathrm{v} 0.5}$ were developed. The developed models were validated based on wind tunnel experimental data. Results showed that: for $\mathrm{D}_{\mathrm{v} 0.1}, \mathrm{D}_{\mathrm{v} 0.5}, \mathrm{D}_{\mathrm{v} 0.9}$ and $\%<150 \mu \mathrm{m}, R^{2}$ were equal to $0.768,0.823,0.868$ and 0.811 , indicating that the predictive ability for these four parameters is strong. For RS and CV, $R^{2}$ were equal to 0.100 and 0.113 , respectively, indicating that the predictive ability for these two parameters is poor. The models developed in the present study are helpful for facilitating the use of AIN in agricultural spray application.
\end{abstract}

Keywords: prediction model, agricultural spray application, droplet characteristics, AIN, laser diffraction DOI: $10.25165 /$ j.ijabe.20191206.5014

Citation: Liao J, Hewitt A J, Wang P, Luo X W, Zang Y, Zhou Z Y, et al. Development of droplet characteristics prediction models for air induction nozzles based on wind tunnel tests. Int J Agric \& Biol Eng, 2019; 12(6): 1-6.

\section{Introduction}

With the increase in use of chemical pesticide applications in crop protection, the consequent risks of the amount of off-target pesticide, the contamination to the environment, the destruction of the ecological resources, the damage to the downwind crops, the harm to the livestock and human health increase simultaneously ${ }^{[1]}$, these problems are of great concern all over the world ${ }^{[2]}$. Pesticide spraying is a very complex process with many factors must to be considered ${ }^{[3]}$. The droplet characteristics $\left(\mathrm{D}_{\mathrm{v} 0.1}, \mathrm{D}_{\mathrm{v} 0.5}\right.$, $\mathrm{D}_{\mathrm{v} 0.9}$, etc.) are most important effect factors of the agricultural spray applications ${ }^{[4,5]}$. Droplet characteristics are significantly influenced by spray parameters (nozzle flowrate, nozzle type, nozzle angle, spray pressure, etc.), chemical and physical properties

Received date: 2019-03-04 Accepted date: 2019-09-28

Biographies: Juan Liao, Post-doctor, research interests: agricultural aviation application, Email: liaojuan0529@126.com; Andrew John Hewitt, Professor, research interests: pesticide application, Email: a.hewitt@uq.edu.au; Pei Wang, Doctor, research interests: agricultural aviation application, Email: wangpei@scau.edu.cn; Ying Zang, Professor, research interests: agricultural mechanization and agricultural aviation application; Zhiyan Zhou, Professor, research interests: agricultural aviation application, Email: zyzhou@scau.edu.cn; Yubin Lan, Professor, research interests: agricultural aviation application, Email: ylan@scau.edu.cn; Chris O'Donnell, Research Fellow, research interests: pesticide application, Email: c.odonnell@uq.edu.au.

*Corresponding author: Xiwen Luo, Professor, research interests: agricultural mechanization. College of Engineering, South China Agricultural University, Guangzhou 510642, China. Tel: +86-20-85280158, Email: xwluo@scau.edu.cn. of the pesticide, air speed and other factors ${ }^{[6]}$. Researchers have been studying to understand the behavior of pesticide spraying for better controlling the spraying behavior to maximize the droplet deposition on the crop leaf surface and minimize the drift proportion to the environment ${ }^{[7]}$. Droplet movement and penetration ${ }^{[8]}$, spray deposition ${ }^{[9]}$ and drift $^{[10,11]}$, and models are the main research focuses for pesticide management in agricultural spray applications.

Predicting and controlling spray behavior are very important approaches to simplify field and wind tunnel tests in agricultural spray applications. The mathematical models and computer simulations are very powerful complement for predicting and controlling the spray behavior under different parameters. The first use of a prototype model was applied to forestry use to determine application rates in testing of insecticides under consideration for forest insect control in 1971. Thompson developed and improved the relation model between atmospheric diffusion and droplet evaporation, drift and deposition. Akesson developed the PARIS program to estimate the spray drift of different atomizers ${ }^{[12]}$. Forest Service Cramer-Barry-Grim (FSCBG), which was developed by the United States Department of Agriculture (USDA) Forest Service in cooperation with the United States Army, is the first model for droplet deposition and drift prediction in aerial spraying ${ }^{[13,14]}$. Agriculture Dispersal (AGDISP) was developed by Spray Drift Task Force (SDTF) based on FSCBG and identified as a valuable software for substantiating drift data which is collected in the extensive aerial field studies. 
AgDRIFT $^{\mathbb{R}[15]}$ was developed by the SDTF cooperate with EPA (Environmental Protection Agency) and USDA based on AGDISP to provide the valuable prediction for aerial studies prior the field tests. These models are great helpful for the pesticide management in agricultural spray applications.

Several technologies for spray drift reduction have been developed over the years to help with spray drift reduction. Air-induction nozzle (AIN) is a very important drift reduction technology (DRT). It discharges large airbubble-containing droplets and reduces the number of small droplets, therefore reduces the spray drift potential. Deciding desired droplet spectrum for each individual application before the spraying application is very important for agricultural spray applications ${ }^{[16]}$. Wind tunne ${ }^{[17]}$ and field studies ${ }^{[18,19]}$ are two traditional approaches for droplet size deciding before spay applications, but they are expensive, time-consuming and labor- intensive. The adoption of model in predicting spraying behavior based on different parameters can provide quick and easy decision-making on desired droplet behavior before spraying application. The model development for AIN is great helpful for its' agricultural spray application, however, not many studies have been done in model building for AIN. Therefore, the modeling research on AIN should be enhanced to facilitate the application of AIN in agricultural spraying.

Nozzle flowrate (a function of nozzle orifice diameter and spray pressure) and spray pressure are two of the most important factors influencing on droplet characteristics, and the droplet size has been proved to be influenced by air speed ${ }^{[20]}$. However, no study has been found for droplet characteristics predicting by input parameters of nozzle flowrate, spray pressure and air speed. The aim of this research was to build the prediction models between input variables of nozzle flowrate, spray pressure and air speed, and the output variables of $\mathrm{D}_{\mathrm{v} 0.1}, \mathrm{D}_{\mathrm{v} 0.5}, \mathrm{D}_{\mathrm{v} 0.9}$, the $\%<150 \mu \mathrm{m}$, relative span $(R S)$ and coefficient of variation $(\mathrm{CV})$ of $\mathrm{D}_{\mathrm{v} 0.5}$ for air-induction nozzles (AINs). And then to help with application decision-making based on the predicted droplet characteristics before spray application. A series of BFS AINs with different nozzle orifice diameters were tested under different spray pressures and air speeds.

\section{Materials and methods}

\subsection{Wind tunnel facilities}

Comparing to the field test, wind tunnel test can simulate the field conditions and has the outstanding advantages of repeatable, consistence, easy accessibility, and short sampling periods, therefore, wind tunnel test has been wildly used for developing of models in pesticide spraying study ${ }^{[21]}$. The tests of this study were carried out in the Centre for Pesticide Application and Safety (CPAS) Wind Tunnel Research Facility at the University of Queensland in Gatton, Queensland, Australia. The arrangement of wind tunnel facilities is shown in Figure 1.

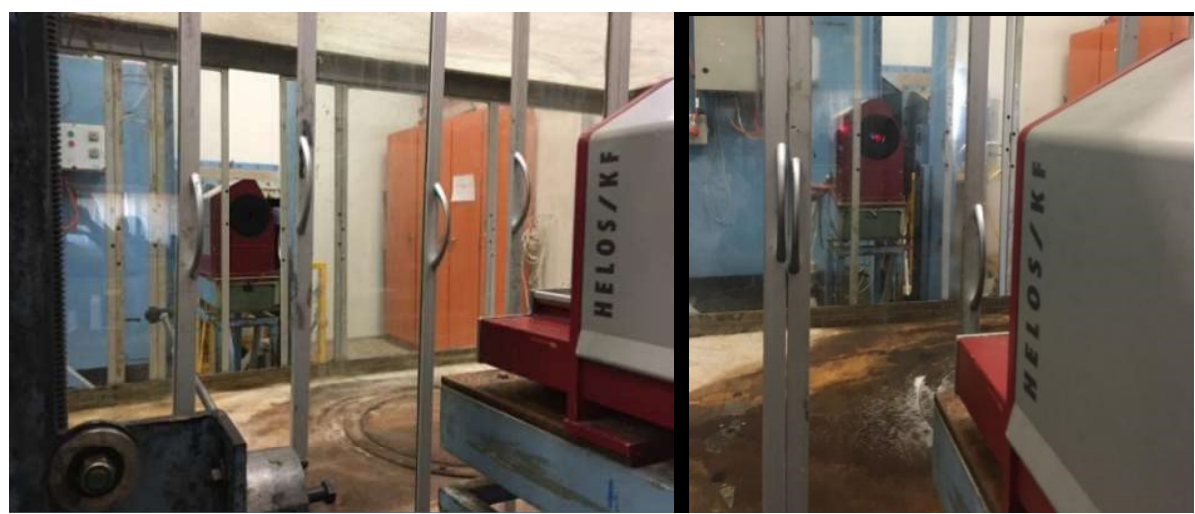

Note: The Helos laser diffraction system was mounted $51 \mathrm{~cm}$ horizontal distance in downwind direction from the nozzle, a distance for the sufficient breakup of the liquid sheet. The spray clouds were oriented perpendicular to the laser beam and crossed the laser beam when measuring.

Figure 1 Arrangement of wind tunnel facilities

\subsection{Laser diffraction analyzer}

A laser diffraction sensor is an optical, spatial, non-intrusive, non-imaging sampling instrument to characterize sprays, it doesn't influence the spray behavior during testing ${ }^{[22]}$. A Helos-Vario laser diffraction system with an R7 lens (Sympatec Inc., Clausthal, Germany) was used in this study. The laser was controlled by Windox 5.70 software operated on the computer, it directs a laser beam unobtrusively through a spray cloud, hence, the droplet characteristics of the entire spray cloud is calculated by the laser light intensity distribution ${ }^{[23]}$. This laser-lens combination is able to detect a dynamic droplet size range of $0.5-3500 \mu \mathrm{m}$. With the aim of ensuring the sufficient measurement of the entire spray cloud in the area of laser beam scanning, the testing nozzle bodies were mounted on a vertical movement actuator, which was controlled by a PLC (Programmable Logic Controller) and moved the nozzles with a constant speed. Each replication of the spray plume has been measured for 9 seconds, and each test was repeated three times to ensure the correct results. Once the $\mathrm{CV}$ of a replication was more than $3 \%$, the results should be removed and the replication should be retested.

\subsection{Measuring scenarios}

Six BFS AINs with different orifice diameters (BFS 11001, BFS 11002, BFS 11004, BFS 11005, BFS 11006 and BFS 11008) in combination with tap water were tested. $0.2 \mathrm{MPa}, 0.3 \mathrm{MPa}$, $0.4 \mathrm{MPa}, 0.5 \mathrm{MPa}, 0.6 \mathrm{MPa}$ and $0.7 \mathrm{MPa}$ of spray pressures and $2 \mathrm{~m} / \mathrm{s}, 3 \mathrm{~m} / \mathrm{s}, 4 \mathrm{~m} / \mathrm{s}$ and $5 \mathrm{~m} / \mathrm{s}$ of air speeds were setup. The test scenarios are shown in Table 1.

Table 1 Spraying scenarios with different nozzle flowrates, spray pressures and air speeds were tested. The nozzle flowrate was decided by the nozzle orifice diameter and spray pressure. For a given nozzle orifice diameter, the flowrate increases with the increase of spray pressure

\begin{tabular}{cccc}
\hline Nozzle & Nozzle flowrate/L·min & $\begin{array}{c}\text { Spray pressure } \\
/ \mathrm{MPa}\end{array}$ & $\begin{array}{c}\text { Air speed } \\
/ \mathrm{m}^{-1} \mathrm{~s}^{-1}\end{array}$ \\
\hline BFS11001 & $0.33,0.40,0.46,0.52,0.57,0.61$ & $0.2,0.3,0.4,0.5,0.6,0.7$ & $2,3,4,5$ \\
BFS11002 & $0.66,0.80,0.92,1.04,1.14,1.24$ & $0.2,0.3,0.4,0.5,0.6,0.7$ & $2,3,4,5$ \\
BFS11004 & $1.31,1.60,1.85,2.07,2.27,2.48$ & $0.2,0.3,0.4,0.5,0.6,0.7$ & $2,3,4,5$ \\
BFS11005 & $1.63,2.00,2.31,2.58,2.82,3.04$ & $0.2,0.3,0.4,0.5,0.6,0.7$ & $2,3,4,5$ \\
BFS11006 & $1.96,2.40,2.77,3.10,3.39,3.64$ & $0.2,0.3,0.4,0.5,0.6,0.7$ & $2,3,4,5$ \\
BFS11008 & $2.61,3.20,3.70,4.13,4.53,4.96$ & $0.2,0.3,0.4,0.5,0.6,0.7$ & $2,3,4,5$
\end{tabular}




\subsection{Droplet characteristics}

The present study focused on the prediction models between nozzle flowrate, spray pressure and air speed and volumetric droplet characteristics of $\mathrm{D}_{\mathrm{v} 0.1}, \mathrm{D}_{\mathrm{v} 0.5}, \mathrm{D}_{\mathrm{v} 0.9}, \%<150 \mu \mathrm{m}$, RS and CV. $\mathrm{D}_{\mathrm{v} 0.5}$ is the volume median diameter (VMD), it is defined as the diameter at which half of the volume of droplets are contained in droplets, $\mathrm{D}_{\mathrm{v} 0.1}$, and $\mathrm{D}_{\mathrm{v} 0.9}$ are defined as the volume diameter below which smaller droplets constitute $10 \%$ and $90 \%$ of the total spray volume, respectively. $\%<150 \mu \mathrm{m}$ is the proportion of spray volume contained in droplets with diameter below $150 \mu \mathrm{m}$. Droplets uniformity in this study was determined by the $\mathrm{CV}$ of spray solution $\mathrm{D}_{\mathrm{v} 0.5}$. And RS denotes the evenness of the spray droplet size spectrum. These droplet characteristic values are very important indices in deciding the spraying deposition on-target and spraying drift to non-target in agricultural spray applications. $\mathrm{D}_{\mathrm{v} 0.5}$ is widely used for spray efficacy evaluation, $\mathrm{D}_{\mathrm{v} 0.1}$ and $\%<$ $150 \mu \mathrm{m}$ are widely used for spray drift potential evaluation, CV and RS are used for evaluation of droplets consistency and uniformity. $\mathrm{CV}$ is calculated as the standard deviation $(\sigma)$ of the $\mathrm{D}_{\mathrm{v} 0.5}$ divided by the mean of the $\mathrm{D}_{\mathrm{v} 0.5}{ }^{[24]}$ :

$$
R S=\frac{D_{v 0.9}-D_{v 0.1}}{D_{v 0.5}}
$$

where, $\sigma_{D_{v 0.5}}$ is the standard deviation of $\mathrm{D}_{\mathrm{v} 0.5} ; \overline{D_{v 0.5}}$ is the mean of $\mathrm{D}_{\mathrm{v} 0.5}$. The smaller the value of $\mathrm{CV}$ is, the more uniform of the $\mathrm{D}_{\mathrm{v} 0.5}$. RS is calculated using the equation as follow:

The closer of the RS is to 1, the better is the evenness of spray droplet size spectrum, and the better is the spray quality.

\subsection{Statistical analysis and modeling}

Input variables and output variables ${ }^{[25]}$ are two of basic elements in mathematical modeling and statistical analysis. Prediction model predicts the values of output variables based on the values of input variables by involving the influence of input variables have on the output variables. In the present study, nozzle flowrate, spray pressure and air speed were defined as input variables, and $\mathrm{D}_{\mathrm{v} 0.1}, \mathrm{D}_{\mathrm{v} 0.5}, \mathrm{D}_{\mathrm{v} 0.9}, \%<150 \mu \mathrm{m}, \mathrm{CV}$ and $\mathrm{RS}$ were defined as output variables. Prediction models were developed by the Statistic Package for Social Science, version 25.0 (SPSS $25.0)^{[26]}$ to predict the values $\mathrm{D}_{\mathrm{v} 0.1}, \mathrm{D}_{\mathrm{v} 0.5}, \mathrm{D}_{\mathrm{v} 0.9}, \%<150 \mu \mathrm{m}, \mathrm{CV}$ and RS by the values of nozzle flowrate, spray pressure and air speed.

Analysis of Variance (ANOVA) was performed to assess the statistical significance between input and output variables and estimate the regression coefficients of prediction models. Means separation for the data was made at $p=0.05$ level and adjusted by Turkey-Kramer's Honestly Significant Difference (HSD) ${ }^{[27] .}$ The $p$-value was used to assess the significant level of prediction models and the validity of the regression coefficients. 0.05 and 0.01 were set as the thresholds for significant and highly significant level ${ }^{[28]}$. The strength and direction of the relationship between the input and output variables is quantified by the Pearson Product-moment Correlation Coefficient $\mathrm{R}$, the value of $\mathrm{R}$ is between -1.0 and $+1.0^{[29]}$, the sign of the correlation coefficient indicates the direction, and the magnitude of the correlation indicates the strength of the relationship ${ }^{[30]}$.

\subsection{Regression fitting}

SPSS 25.0 was employed for validation of prediction models by regression fitting. When SPSS is used for regression fitting, fitting correlation coefficient quantifies the proportion of the output variables that is predicable from the input variables, it is expressed by $R^{2}$ ( $R$ square) and ranging from 0 to $1^{[31]}$.

(i) $R^{2}=0$, the input variable cannot predict the output variable; (ii) $R^{2}=1$, the input variable can predict the output variable without error;

(iii) $0<R^{2}<1, R^{2}=0.1$ means that $10 \%$ of the values of output variable are predictable from input variables, i.e.

\section{Results}

\subsection{ANOVA}

SS, $F$ and $p$-value are very important indices for assessing prediction model. SS, the sum of square, it denotes the partitioning of sums of squared deviations or errors ${ }^{[32,33]} . F$, variance of the group means. The influences significance of nozzle flowrate, spray pressure and air speed on droplet characteristics were analyzed by ANOVA before model developing. Nozzle flowrate and spray pressure were observed to have significant influence on droplet characteristics while the range of air speed from $2 \mathrm{~m} / \mathrm{s}$ (probably lower) to $5 \mathrm{~m} / \mathrm{s}$ (probably higher) had no significant influence on droplet characteristics of AINs. These results revealed that the air speed ranged from $2 \mathrm{~m} / \mathrm{s}$ to $5 \mathrm{~m} / \mathrm{s}$ could not be as an input variable for the prediction models, because its' contribution to the prediction model was rather limited compare with nozzle flowrate and spray pressure. The ANOVA for statistical significance between input variables and each output variable were carried out, the statistical summaries are shown in Table 2.

Table 2 Summaries of ANOVA for assessing the statistical significance between dependent and independent variables

\begin{tabular}{ccccc}
\hline Dependent variable & $S S$ & $F$ & $p$-value & Sig. \\
\hline $\mathrm{D}_{\mathrm{v} 0.1}$ & 19221.215 & 114.392 & 0.000 & $* *$ \\
$\mathrm{D}_{\mathrm{v} 0.5}$ & 111099.617 & 160.220 & 0.000 & $* *$ \\
$\mathrm{D}_{\mathrm{v} 0.9}$ & 336571.824 & 227.060 & 0.000 & $* *$ \\
$\%<150 \mu \mathrm{m}$ & 841.405 & 137.975 & 0.000 & $* *$ \\
$R S$ & 0.032 & 3.818 & 0.027 & $*$ \\
$C V$ & 29.756 & 4.375 & 0.016 & $*$ \\
\hline
\end{tabular}

Note: '**', '*' and '-' indicates respectively that the regression model is at highly significant, significant and not significant level.

Table 2 shows that, the prediction models for $\mathrm{D}_{\mathrm{v} 0.1}, \mathrm{D}_{\mathrm{v} 0.5}, \mathrm{D}_{\mathrm{v} 0.9}$ and $\%<150 \mu \mathrm{m}$ are at highly significant level, while the prediction models for RS and CV are at significant level. However, the significance of each regression coefficient for prediction models should be analyzed (hereinafter). If the regression coefficient(s) of one or more input variable(s) was (were) invalid ( $p>0.05)$, the prediction model should be established without the invalid regression coefficient(s).

\subsection{Development of prediction models}

Regression analysis was performed by SPSS to understand which input variable(s) is (are) correlating with the output variable, and to explore the prediction models between input and output variables. For the prediction model, the equation between input variables and output variable is as follow:

$$
\hat{y}_{i}=\beta_{i 0}+\beta_{i 1} x_{i 1}+\beta_{i 2} x_{i 2}+\ldots+\beta_{i j} x_{i j}+e_{i}
$$

where, $\hat{y}_{i}$ is the predicted value of the output variable; $\beta_{0}$ is a constant term estimated by regression analysis; $\beta_{i 1}$ through $\beta_{i j}$ are the estimated regression coefficients; $x_{i 1}$ through $x_{i j}$ are $j$ distinct input variables for $i$ distinct out variable; $e_{i}$, also known as residual, it is the deviation between the actual value and the predicted value. In the present study, there are six of output variables, including $\mathrm{D}_{\mathrm{v} 0.1}, \mathrm{D}_{\mathrm{v} 0.5}, \mathrm{D}_{\mathrm{v} 0.9}, \%<150 \mu \mathrm{m}$, RS and $\mathrm{CV}$, and two input variables, including nozzle flowrate and spray pressure. Therefore, $i=1,2,3$, $4,5,6$ and $j=1,2 . \quad \hat{y}_{1}=\mathrm{D}_{\mathrm{v} 0.1}, \quad \hat{y}_{2}=\mathrm{D}_{\mathrm{v} 0.5}, \quad \hat{y}_{3}=\mathrm{D}_{\mathrm{v} 0.9}, \quad \hat{y}_{4}=\%<150 \mu \mathrm{m}$, 
$\hat{y}_{5}=\mathrm{CV}, \quad \hat{y}_{6}=\mathrm{RS} . \quad x_{1}=$ nozzle flowrate, $x_{2}=$ spray pressure. $\quad \beta_{\mathrm{i} 1}$ is the regression coefficient of nozzle flowrate, and $\beta_{\mathrm{i} 2}$ is the regression coefficient of spray pressure. In this study, 144 samples were got from the test, 72 samples were chose randomly for prediction models development, and the 72 remaining samples were used for validation of the prediction models. The coefficient and significance of models were summarized and shown in Table 3.

Table 3 shows that, all the estimated regression coefficients for
$\mathrm{D}_{\mathrm{v} 0.1}, \mathrm{D}_{\mathrm{v} 0.5}, \mathrm{D}_{\mathrm{v} 0.9}$ and $\%<150 \mu \mathrm{m}$ are valid, it means that these four variables can be predicted by the nozzle flowrate and spray pressure with the prediction models. For RS, only the coefficient of constant is valid, hence, the values of RS under different nozzle flowrate and spray pressure are all equal to 1.290 . For CV, the coefficients of constant and nozzle flowrate are valid, the minus value of coefficient of nozzle flowrate proved that $\mathrm{CV}$ decreases with the increase of nozzle flowrate.

Table $3 \beta_{i 0}$ through $\beta_{i 2}$ are the estimated regression coefficients for the $i^{\text {th }}$ output variables. $p$-value indicates the validity of estimated regression coefficients, $p$-value $>0.05$ and '-' indicate the invalidity of estimated regression coefficients

\begin{tabular}{|c|c|c|c|c|c|c|c|c|c|c|}
\hline Output variable & $\beta_{\mathrm{i} 0}$ & $p$-value & Sig. & $\beta_{\mathrm{i} 1}$ & $p$-value & Sig. & $\beta_{\mathrm{i} 2}$ & $p$-value & Sig. & $e_{\mathrm{i}}$ \\
\hline $\mathrm{D}_{\mathrm{v} 0.1}$ & 169.654 & 0.000 & $* *$ & 11.268 & 0.000 & $* *$ & -11.551 & 0.000 & $* *$ & 9.036 \\
\hline $\mathrm{D}_{\mathrm{v} 0.5}$ & 388.554 & 0.000 & $* *$ & 26.479 & 0.000 & $* *$ & -28.428 & 0.000 & $* *$ & 18.356 \\
\hline $\mathrm{D}_{\mathrm{v} 0.9}$ & 659.179 & 0.000 & $* *$ & 49.759 & 0.000 & $* *$ & -45.127 & 0.000 & $* *$ & 26.838 \\
\hline$\%<150 \mu \mathrm{m}$ & 6.388 & 0.000 & $* *$ & -2.361 & 0.000 & $* *$ & 2.413 & 0.000 & $* *$ & 1.721 \\
\hline RS & 1.290 & 0.000 & $* *$ & 0.011 & 0.090 & - & 0.012 & 0.091 & - & 0.065 \\
\hline
\end{tabular}

Based on the results analysis of Table 3, the prediction models between input variables and each output variable were summarized as in Table 4.

Table 4 Summaries of multiple linear regression models between independent variables and each dependent variable

\begin{tabular}{cl}
\hline Input variables-output variable & \multicolumn{1}{c}{ Regression model } \\
\hline Input variables- $\mathrm{D}_{\mathrm{v} 0.1}$ & $\hat{y}_{1}=169.654+11.268 x_{1}-11.551 x_{2}$ \\
Input variables- $\mathrm{D}_{\mathrm{v} 0.5}$ & $\hat{y}_{2}=388.544+26.479 x_{1}-28.428 x_{2}$ \\
Input variables- $\mathrm{D}_{\mathrm{v} 0.9}$ & $\hat{y}_{3}=659.179+49.759 x_{1}-45.127 x_{2}$ \\
Input variables- $\%<150 \mu \mathrm{m}$ & $\hat{y}_{4}=6.388-2.361 x_{1}+2.413 x_{2}$ \\
Input variables-RS & $\hat{y}_{5}=1.249$ \\
Input variables-CV & $\hat{y}_{6}=3.382-0.496 x_{1}$ \\
\hline
\end{tabular}

\subsection{Validation of prediction models}

Regression fitting ${ }^{[34]}$ can explain the fitness of a series of data points. In this study, the availability of prediction models was validated by the discrepancy between experimental and predicted values of output variables ${ }^{[35]}$, and the discrepancy were demonstrated by regression fitting.

Results concluded from Figure 2a-f are as follows:

(a) For $\mathrm{D}_{\mathrm{v} 0.1}, R=0.877$ and $R^{2}=0.768$, indicating that nozzle flowrate and spray pressure have highly significant correlation with $D_{v 0.1}, 76.8 \%$ of the $D_{v 0.1}$ values are predictable by nozzle flowrate and spray pressure.

(b) For $\mathrm{D}_{\mathrm{v} 0.5}, R=0.907$ and $R^{2}=0.823$, indicating that nozzle flowrate and spray pressure have highly significant correlation with $\mathrm{D}_{\mathrm{v} 0.5}, 82.3 \%$ of the $\mathrm{D}_{\mathrm{v} 0.5}$ values are predictable by nozzle flowrate and spray pressure.
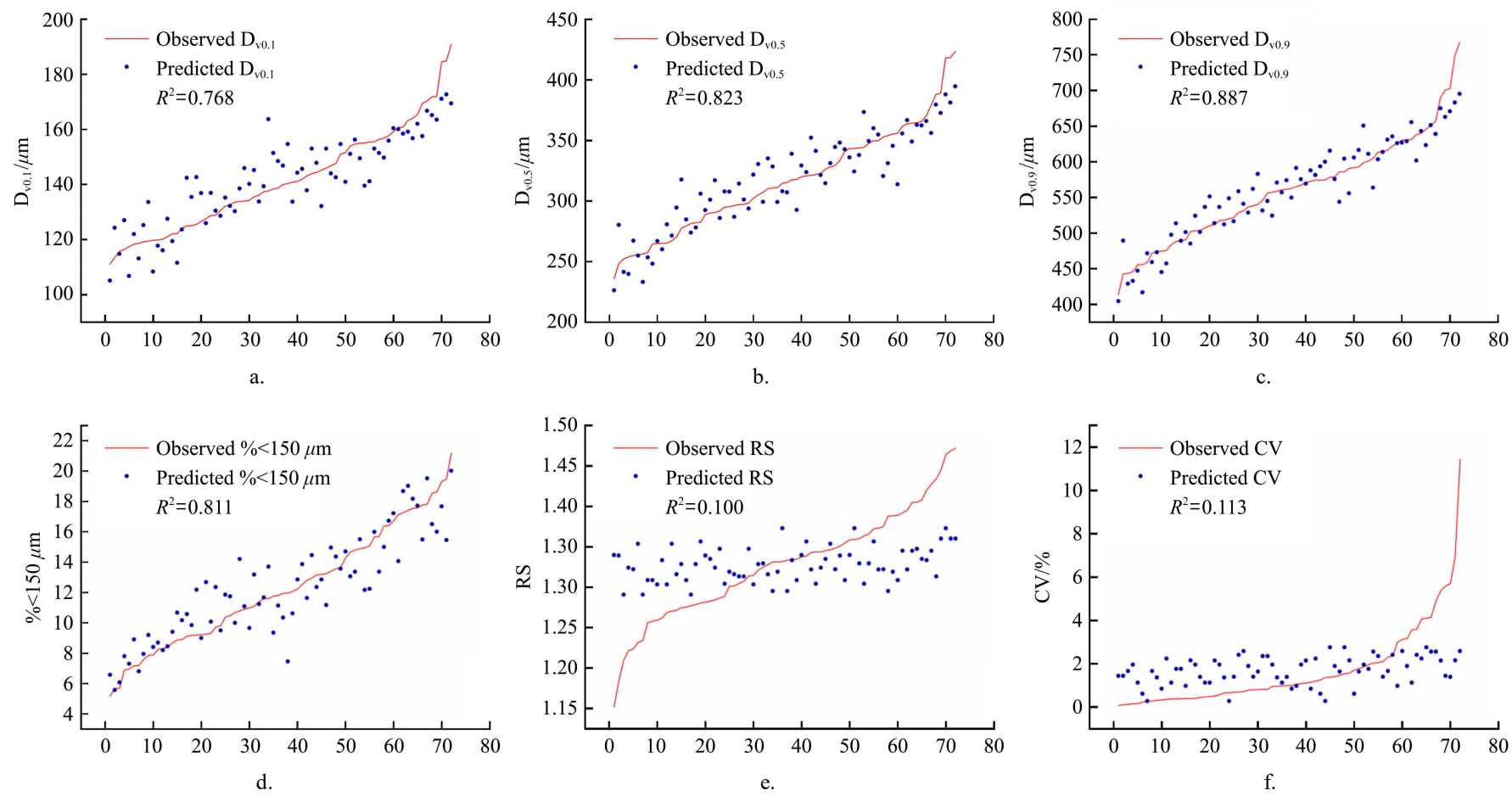

Note: The $Y$-axis denotes the values of droplets characteristics and the $X$-axis denotes the numbers of sample points.

Figure 2 Regression fitting was adopted in comparing the deviation between the observed and predicted values of $D_{v 0.1}, D_{v 0.5}, D_{v 0.9}$, and $\%<150 \mu \mathrm{m}$, RS and CV 
(c) For $\mathrm{D}_{\mathrm{v} 0.9}, R=0.932$ and $R^{2}=0.868$, indicating that nozzle flowrate and spray pressure have highly significant correlation with $\mathrm{D}_{\mathrm{v} 0.9}, 86.8 \%$ of the $\mathrm{D}_{\mathrm{v} 0.9}$ values are predictable by nozzle flowrate and spray pressure.

(d) For $\%<150 \mu \mathrm{m}, R=0.894$ and $R^{2}=0.811$, indicating that nozzle flowrate and spray pressure have highly significant correlation with $\%<150 \mu \mathrm{m}, 81.1 \%$ of the $\%<150 \mu \mathrm{m}$ values are predictable by nozzle flowrate and spray pressure.

(e) For RS, $R=0.316$ and $R^{2}=0.100$, indicating that nozzle flowrate and spray pressure have low correlation with RS, only $10 \%$ of the RS values are predictable by nozzle flowrate and spray pressure.

(f) For $\mathrm{CV}, R=0.335$ and $R^{2}=0.113$, indicating that the independent variables have low correlation with CV, only $11.3 \%$ of the $\mathrm{CV}$ values are predictable by nozzle flowrate and spray pressure.

\section{Discussion}

This study explored the prediction models between input variables of nozzle flowrate, spray pressure and air speed, and output variables of $\mathrm{D}_{\mathrm{v} 0.1}, \mathrm{D}_{\mathrm{v} 0.5}, \mathrm{D}_{\mathrm{v} 0.9}, \%<150 \mu \mathrm{m}$, RS and CV. The experimental results showed that: (1) The air speed (ranged from $2 \mathrm{~m} / \mathrm{s}$ to $5 \mathrm{~m} / \mathrm{s}$ ) cannot be an input parameter for prediction model in droplet characteristics prediction. (2) The prediction model based on nozzle flowrate and spray pressure had a strong predictive ability for $\mathrm{D}_{\mathrm{v} 0.1}, \mathrm{D}_{\mathrm{v} 0.5}, \mathrm{D}_{\mathrm{v} 0.9}$ and $\%<150 \mu \mathrm{m}$. However, the predictive ability of prediction models for RS and $\mathrm{CV}$ based on nozzle flowrate and spray pressure were very poor.

Because the contribution of air speed (ranged from $2 \mathrm{~m} / \mathrm{s}$ to $5 \mathrm{~m} / \mathrm{s}$ ) to the prediction models was not significant, this range of air speed cannot be an input parameter for prediction model in droplet characteristics prediction. Hoffmann ${ }^{[36]}$ reported that the droplet size parameters $\left(D_{v 0.1}, D_{v 0.5}\right.$ and $\left.D_{v 0.9}\right)$ increased as the air speed increased from $0.6 \mathrm{~m} / \mathrm{s}$ to $2.2 \mathrm{~m} / \mathrm{s}$ and slightly decreased when the air speed increased from $2.2 \mathrm{~m} / \mathrm{s}$ to $4.9 \mathrm{~m} / \mathrm{s}$ in the wind tunnel. This report indicated that the air speed ranged from $2.2 \mathrm{~m} / \mathrm{s}$ to $4.5 \mathrm{~m} / \mathrm{s}$ had an influence on droplet size parameters. However, the test results of the present study demonstrated that the air speed ranged from $2 \mathrm{~m} / \mathrm{s}$ (probably lower) to $5 \mathrm{~m} / \mathrm{s}$ (probably higher) had a very limited contribution to the prediction models comparing to the nozzle flowrate and spray pressure.

The fitting correlation coefficient $R^{2}$ for prediction models of $\mathrm{D}_{\mathrm{v} 0.1}, \mathrm{D}_{\mathrm{v} 0.5}$ and $\mathrm{D}_{\mathrm{v} 0.9}$ were equal to $0.768,0.823$ and 0.868 , respectively. Hence, comparing the predictive abilities of prediction models for different droplet diameter sizes parameters, the prediction model for $\mathrm{D}_{\mathrm{v} 0.9}$ had the most effective predictive ability and followed by $\mathrm{D}_{\mathrm{v} 0.5}$ and $\mathrm{D}_{\mathrm{v} 0.1}$, it indicated that the predictive ability increased with the increase of droplet diameter size. The fitting correlation coefficient $R^{2}$ for prediction models for RS and CV were equal to 0.100 and 0.113 , respectively, it indicated that the predictive abilities of these models were very poor. It is because the value of RS is calculated by $D_{v 0.1}, D_{v 0.5}$ and $\mathrm{D}_{\mathrm{v} 0.9}$, and the value of $\mathrm{CV}$ is calculated by $\mathrm{D}_{\mathrm{v} 0.5}$, the values of RS and $\mathrm{CV}$ are depending on droplet diameter size parameters, hence, the values of RS and CV cannot be predicted directly by nozzle flowrate and spray pressure.

\section{Conclusions}

In the present study, with the aim to understand the spray behavior of AIN under different parameters of nozzle flowrates and spray pressures and build prediction models for AIN, six BFS AINs with different orifice diameters under different spray pressures and air speed were tested. Comparing to the nozzle flowrate and spray pressure, the contribution of air speed to the prediction models as an input variable was very poor. Hence, the prediction models were developed to predict the output variables of $\mathrm{D}_{\mathrm{v} 0.1}, \mathrm{D}_{\mathrm{v} 0.5}$, $\mathrm{D}_{\mathrm{v} 0.9}, \%<150 \mu \mathrm{m}, \mathrm{RS}$ and $\mathrm{CV}$ by the input variables of nozzle flowrate and spray pressure. The prediction abilities of prediction models were validated based on the wind tunnel tests data. Validation results showed that $\mathrm{D}_{\mathrm{v} 0.1}, \mathrm{D}_{\mathrm{v} 0.5}, \mathrm{D}_{\mathrm{v} 0.9}$ and $\%<150 \mu \mathrm{m}$ can be predicted by input variables of nozzle flowrate and spray pressure, while RS and CV cannot by predicted by these two input variables. The prediction models can help applicators with making spraying decision by predicting $\mathrm{D}_{\mathrm{v} 0.1}, \mathrm{D}_{\mathrm{v} 0.5}, \mathrm{D}_{\mathrm{v} 0.9}$ and $\%<150 \mu \mathrm{m}$ based on the values of nozzle flowrate and spray pressure prior to agricultural spray application.

\section{Acknowledgements}

This work was financially supported by the National Natural Science Foundation of China (31901401 and 31871520), the National Key R\&D Program of China (2018YFD0200301), Science and Technology Plan of Guangdong Province of China (2017B090903007), Innovative Research Team of Guangdong Province Agriculture Research System (2017LM2153), Science and Technology Plan of Guangdong Province of China (2017B090907031) and the Natural Science Foundation of Jiangsu Province (Project No. BK20160510). Authors would like to thank the Centre for Pesticide Application and Safety (CPAS), the University of Queensland, Gatton, Australia, for providing necessary support for this study, such as wind tunnel and corresponding facilities, nozzles, etc.

\section{[References]}

11] Faical B S, Ueyama J, de Carvalho A C P L F. The use of autonomous UAVs to improve pesticide application in crop fields. 17th IEEE International Conference on Mobile Data Management (MDM), IEEE, Porto, Portugal, 2016. DOI: 10.1109/MDM.2016.96

[2] Craig D O, Fernandez-Cornejo J. Economic and policy issues of U.S. agricultural pesticide use trends. Pest Manag Sci, 2013; 69(9): 1001-1025.

[3] Rincón V J, Sánchez-Hermosilla J, Páez F, Pérez-Alonso J, Callejón Ángel J. Assessment of the influence of working pressure and application rate on pesticide spray application with a hand-held spray gun on greenhouse pepper crops. Crop Prot, 2017; 96: 7-13.

[4] Hoffmann W C, Hewitt A J, Ross J B. Spray adjuvant effects on droplet size spectra measured by three laser-based systems in a high-speed wind tunnel. Journal of ASTM International, 2008; 5(6): 1-12.

[5] Fritz B K, Hoffmann W C, Kruger G R, Henry R S, Hewitt A J, Czaczyk Z. Comparison of drop size data from ground and aerial application nozzles at three testing laboratories. Atomization Spray, 2014; 24(2): 181-192.

[6] Meng Y H, Lan Y B, Mei G Y, Guo Y W, Song J L, Wang Z G. Effect of aerial spray adjuvant applying on the efficiency of small unmanned aerial vehicle for wheat aphids control. Int J Agric \& Biol Eng, 2018; 11(5): 46-53.

[7] Fritz B K, Hoffmann W C, Martin D E, Thomson S J. Aerial Application Methods for Increasing Spray Deposition on Wheat Heads. Appl Eng Agric, 2007; 23(6): 709-715.

[8] Nuyttens D, De Schampheleire M, Baetens K and Pieter V. Drift from field crop sprayers using an integrated approach: results of a 5 year study. Transactions of ASABE, 2011; 54(2): 403-408.

[9] Zhang D Y, Chen L P, Zhang R R, Xu G, Lan Y B, Hoffmann W C, et al. Evaluating effective swath width and droplet distribution of aerial spraying systems on M-18B and Thrush 510G airplanes. Int J Agric \& Biol Eng, 2015; 8(2): 21-30.

[10] Wang J, Lan Y B, Zhang H H, Zhang Y L, Wen S, Yao W X et al. Drift and deposition of pesticide applied by UAV on pineapple plants under 
different meteorological conditions. Int J Agric \& Biol Eng, 2018; 11(6): $5-12$.

[11] Wang X N, He X K, Song J L, Wang Z C, Wang C L, Wang S L, et al. Drift potential of UAV with adjuvants in aerial applications. Int J Agric \& Biol Eng, 2018; 11(5): 54-58.

[12] Akesson N B, Gibbs R E. Pesticide drop size as a function of spray atomizers and liquid formulations. Pesticide Formulations and Application Systems, 1990; 10: 170-183.

[13] Teske M E, Bowers J F, Rafferty J E, Baetens K, Barry J W. FSCBG: an aerial spray dispersion model for predicting the fate of released material behind aircraft. Environ Toxicol Chem, 1993; 12: 453-464.

[14] Barry J W, Skyler P J, Teske M E, Rafferty J A, Grim B S. Predicting and measuring drift of Bacillus thuringiensis sprays. Environ Toxicol Chem, 1993; 12: 1977-1989.

[15] Teske M E, Bird S L, Esterly D M, Curbishley T B, Ray S L, Perry SG. AgDRIFT: a model for estimating near-field spray drift from aerial applications. Environ Toxicol Chem, 2002; 21(3): 659-671.

[16] Krueger S, Cantrell W, Niedermeier D. An economical model for simulating droplet spectrum evolution in turbulent cloud chambers and wind tunnels. APS Meeting, APS, New Orleans, LA, US, 2017.

[17] Hoffmann W C, Fritz B K, Lan Y B, Zollinger R, Rhode A, Dean S W. Evaluation of a Proposed Drift Reduction Technology High-Speed Wind Tunnel Testing Protocol. Journal of ASTM International, 2009; 6(4): $102-122$

[18] Yao W, Lan Y B, Wen S, Zhang H H, Zhang Y L, Wang J, et al. Evaluation of droplet deposition and effect of variable-rate application by a manned helicopter with AG-NAV Guía system. Int J Agric \& Biol Eng. 2019; 12(1): 172-178

[19] Chen S D, Lan Y B, Li J Y, Zhou Z Y, Liu A M, Mao Y D. Effect of wind field below unmanned helicopter on droplet deposition distribution of aerial spraying. Int J Agric \& Biol Eng, 2017; 10(3): 67-77.

[20] Hoffmann C W, Fritz K B, Bagley W E, Lan Y B. Effects of air speed and liquid temperature on droplet size. Journal of ASTM International, 2011; 8(4): 1-9.

[21] Butler Ellis M C, Alanis R, Lane A G, Tuck C R, Nuyttens D, van de Zande J C. Wind tunnel measurements and model predictions for estimating spray drift reduction under field conditions. Biosyst Eng, 2017; 154: 25-34.

[22] Eshel G, Levy G J, Mingelgrin U, Singer M J. Critical evaluation of the use of laser diffraction for particle-size distribution analysis. Soil Sci Soc
Am J, 2004; 68(3): 736-743.

[23] Nicholls J W, Dorr G J, Woods N, Hewitt A J. Anti-drift adjuvants?: a droplet spectra study. Aspects of Applied Biology, 2004; 71: 175-182.

[24] Brian E. The Cambridge Dictionary of Statistics. Cambridge University Press, Cambridge, U K, 1998. ISBN: 0521593468.

[25] Lotfi S, Rem P, Deja J, Mróz R. An experimental study on the relation between input variables and output quality of a new concrete recycling process. Constr Build Mater, 2017; 137: 128-140.

[26] SPSSS. 19.0. 0 for Windows Software. SPSS Inc., IBM Company, USA, 2010.

[27] Zoz F, Iaconelli C, Lang E, Iddir H, Guyot S, Grandvalet C, et al. Control of Relative Air Humidity as a Potential Means to Improve Hygiene on Surfaces: A Preliminary Approach with Listeria monocytogenes. Plos One, 2016; 11(2): 1-14

[28] Nuzzo R. Scientific method: Statistical errors. Nature, 2014; 506(7484): $150-152$.

[29] Libraries KSU. SPSS Tutorials: Pearson Correlation. http://libguides.library.kent.edu/SPSS/PearsonCorr, 2017.

[30] Külz A K, Landmann S, Cludius B, Hottenrott B, Rose N, Heidenreich T, et al. Mindfulness-based cognitive therapy in obsessive-compulsive disorder: protocol of a randomized controlled trial. Bmc Psychiatry, 2014 14(314): 1-9.

[31] Nagelkerke N J D. A note on a general definition of the coefficient of determination. Biometrika, 1991; 78(3): 691-692.

[32] Bailey R A. Design of comparative experiments. Cambridge University Press, Cambridge, U K, 2008, ISBN: 9780511394188.

[33] Cortina J M, Green J P, Keeler K R, Vandenberg R J. Degrees of freedom in SEM: Are we testing the models that we claim to test? Organ Res Methods, 2017; 20(3): 350-378.

[34] Brewer K, Bareiss C. Concise guide to computing foundations: Core concepts and select scientific applications. Springer, Cham, New York, U S, 2016. ISBN: 978-3-319-29954-9.

[35] Maszczyk P, Babkiewicz E, Czarnockacieciura M, Maciej Gliwicz Z, Gliwicz M, Urban P. Ideal free distribution of Daphnia under predation risk-model predictions and experimental verification. Journal of Plankton Research, 2018; 40(4): 471-485.

[36] Hoffman W C, Fritz B K, Farooq M, Cooperband M F. Effects of wind speed on aerosol spray penetration in adult mosquito bioassay cages. Journal of the American Mosquito Control Association, 2008; 24(3): 419-426. 